\title{
THE ROLE OF BASIC PHARMACOTHERAPY IN THE PREVENTION OF LATE ADVERSE EVENTS AFTER ELECTIVE CORONARY ARTERY BYPASS GRAFTING
}

DOI: 10.36740/WLek202005109

\author{
Olga A. Yepanchintseva ${ }^{1,2}$, Kyrylo 0. Mikhaliev² ${ }^{2}$ Inga V. Shklianka ${ }^{3}$, Oleg J. Zharinov ${ }^{1}$, Boris M. Todurov ${ }^{3}$ \\ 'SHUPYK NATIONAL MEDICAL ACADEMY OF POSTGRADUATE EDUCATION, KYIV, UKRAINE \\ ¿STATE INSTITUTION OF SCIENCE «RESEARCH AND PRACTICAL CENTER OF PREVENTIVE AND CLINICAL MEDICINE» STATE ADMINISTRATIVE \\ DEPARTMENT, KYIV, UKRAINE \\ ${ }^{3}$ HEART INSTITUTE OF THE MINISTRY OF HEALTH OF UKRAINE, KYIV, UKRAINE
}

\begin{abstract}
The aim: To determine the role of adherence to the guidelines on basic pharmacotherapy in prevention of late major adverse clinical events (MAEs) in patients with stable CAD for three years following isolated CABG.

Materials and methods: A prospective single-centre study included 251 consecutive patients with stable CAD (mean age (61 \pm 9$)$ years, 218 (86.9\%) males), after isolated CABG. In three years MAEs occurred in 55 (21.9\%) patients. The data on pharmacotherapy at follow-up were obtained in 250 patients: 196 (78.4\%) patients without MAEs (at scheduled visit) and 54 (21.6\%) patients with MAEs (based on in-hospital or archive data).

Results: Basic CAD pharmacotherapy after CABG was comparable in MAEs vs. no-MAEs groups, with the vast majority of patients receiving guideline-recommended therapy with angiotensin-converting enzyme inhibitors (ACEII) or angiotensin-II receptors blockers (ARBs), statins and antiplatelet drugs. At three years follow-up, MAEs group, as opposed to no-MAEs group, was characterized by the lower usage of ACEII/ARBs $(68.5 \%$ vs. $87.2 \%$, respectively; $p=0,001)$ and statins $(59.3 \%$ vs. $86.7 \%$, respectively; $p<0,001)$, as well as basic triple therapy (ACEIl or ARBs/statins/antiplatelet drugs: $35.2 \%$ vs. $70.4 \%$, respectively $[p<0,001]$ ).

Conclusions: At three - year follow-up MAEs in patients with stable CAD after CABG were associated with more frequent discontinuation of previously prescribed basic pharmacotherapy, namely ACEII/ARBs and statins, as well as triple therapy (ACEII/ARBs, statins and antiplatelet drugs).
\end{abstract}

KEY WORDS: coronary artery disease, coronary artery bypass grafting, pharmacotherapy, late events

Wiad Lek. 2020;73(5):883-888

\section{INTRODUCTION}

Coronary artery bypass grafting (CABG) is the most reliable and effective method of restoration of impaired coronary blood flow in patients with stable coronary artery disease (CAD), especially in the case of multi-vessel coronary lesions. The course of coronary atherosclerosis and the risk of cardiovascular events after surgical revascularization of myocardium may depend on compliance with guidelines on basic medical treatment of stable CAD [1-3]. It always includes antiplatelet drugs (acetylsalicylic acid (ASA), often in combination with clopidogrel), statins, and in most cases - renin-angiotensin system (RAS) blockers (angiotensin converting enzyme inhibitors (ACEI) or angiotensin-II receptor blockers [ARBs]) $[1,2]$. In the presence of left ventricular (LV) systolic dysfunction and heart failure (HF), beta-blockers (BB) and mineralocorticoid receptor antagonist $[1,2,4]$ are indicated.

There is still a significant gap between evidence-based medicine and actual clinical practice, which is largely due to the insufficient risk factor correction and poor adherence to drug therapy [5-7]. Only a few studies of the long-term survival prognosis of patients after elective surgical revascularization of the myocardium have been carried out in the context of the real use of pharmacotherapeutic agents for secondary prevention of cardiovascular events [3, 8-10]. Such studies are crucial for the developement of recommendations on dosing of certain groups of basic drugs and establishment of duration of their use.

\section{THE AIM}

Aim of the study was to determine the role of adherence to the guidelines on basic pharmacotherapy in prevention of late major adverse clinical events (MAEs) in patients with stable CAD for three years following isolated CABG.

\section{MATERIALS AND METHODS}

A prospective, single-centre study analyzed data from a clinical and instrumental examination of 251 consecutive patients with stable CAD, selected for isolated CABG in 2011-2016, with available data of a three-year follow-up. 
The study was conducted in compliance with the basic provisions of the Council of Europe Convention on Human Rights and Biomedicine, World Medical Association Declaration of Helsinki on the ethical principles of conducting human medical research and current regulations of the Ministry of Health of Ukraine. The protocol of the study was approved by the local ethics commission. All patients signed an informed consent to participate in the study.

The study did not include patients in their first month after acute coronary syndromes, as well as those with any condition that made it impossible to perform CABG. In addition, patients were excluded whose CABG was combined with prosthetics of heart valves.

Among the evaluated patients there were 218 (86.9\%) men and 33 (13.1\%) women aged 39 to 92 , mean age (mean \pm standard deviation) $(62 \pm 9)$ years.

$242(96.4 \%)$ patients were diagnosed with stable exertional angina: grade II in $33(13.6 \%)$ patients, grade III - $162(67.0 \%)$ patients, grade IV - 47 (19.4\%) patients. Postinfarction cardiosclerosis was registered in 196 (78.1\%) patients. 40 (15.9\%) of the evaluated patients had a recurrent myocardial infarction, 56 (22.3\%) had left ventricular aneurysm. Coronary arteries stenting (CAS) had been performed earlier in $14(5.6 \%)$ patients. 245 patients (97.6\%) presented signs of chronic HF at rest.

$238(94.8 \%)$ patients had hypertension: $3(1.3 \%)$ patients - stage II -, 235 (98.7\%) - III. A past history of stroke or transient ischemic attack were found in 27 patients (10.8\%).

Atrial fibrillation was registered in $32(12.8 \%)$ patients: 16- paroxysmal, 4 - persistent, 12 patients - permanent. In addition, atrial flutter was found in $2(0.8 \%)$ patients.

Type 2 diabetes mellitus (DM) was diagnosed in 72 (28.7\%) patients: mild $-8(11.1 \%)$, moderate $-31(43.1 \%)$, severe - 33 (45.8\%). Among them, in 7 (9.7\%) patients, glycemic control was considered compensated, in 46 (63.9\%) subcompensated, in 19 (26.4\%) - decompensated. Chronic obstructive pulmonary disease was detected in $6(2.4 \%)$, bronchial asthma - in $3(1.2 \%)$ patients. Signs of chronic kidney disease (CKD) according to KDIGO criteria [11] were present in 75 (29.9\%) patients.

In the perioperative period, all patients received pharmacotherapy according to the current recommendations $[2,4,12]$.

Venous grafts were implanted in the vast majority of patients (97.2\%). In addition, 45 (17.9\%) patients received arterial graft implantation. Along with CABG the following interventions were also performed: LV plastic repair - in 55 (21.9\%) patients; mitral valve plastic repair - 30 (12.0\%); tricuspid valve plastic repair- 14 (5.6\%); reduction of papillary muscles $-3(1.2 \%)$; interventricular septal plastic repair- $2(0.8 \%)$; plastic repair of the interatrial septum - 1 $(0.4 \%)$. The vast majority of interventions $(88.9 \%)$ were performed under artificial blood circulation (on-pump), with aortic cross-clamp (87.7\%).

The pattern of cardiovascular pharmacotherapy at the end of hospital follow-up was as follows: 202 (80.5\%) - ACEII, 16 (6.4\%) - ARBs (total ACEII/ ARBs - 218 [86.9\%]), $173(68.9 \%)$ - mineralocorticoid-receptor an- tagonists, $239(95.2 \%)$ - BB, 51 (20.3\%) - calcium channel blockers, 14 (5.6\%) - thiazide / thiazide-like diuretics, 176 (70.1\%) - loop diuretics (in general, diuretics were prescribed to 180 (71.7\%) patients), 68 (27.1\%) - amiodarone, 248 (98.8\%) - statins, 66 (29.3\%) - nitrates / sydnone imines, 212 (84.5\%) - ASA, 234 (93.2\%) - clopidogrel (in general, anti-platelet therapy (APT) was prescribed to 249 (99.2\%) patients, dual antiplatelet therapy - 197 [78.5\%]). In addition, oral anticoagulants were prescribed to 49 (19.5\%) patients, oral antihyperglycemic drugs - to 41 (16.3\%), insulin - to $18(7.2 \%)$.

During a three-year follow-up of 251 patients the following MAEs were registered: death - 11 (4.4\%) (9 of them - related to cardiovascular causes); myocardial infarction - 4 (1.6\%); unstable angina - 11 (4.4\%); stroke - 5 (2.0\%); decompensated HF - 20 (8.0\%); sustained ventricular tachycardia $-3(1.6 \%)$; repeat myocardial revascularization - 10 (4.0\%); peripheral artery embolism- 1 (0.4\%). To sum up, MAEs occurred in 55 (21.9\%) patients.

Data on taking drugs in patients without MAEs were obtained at the scheduled follow-up visit of patient after 3 years (36 months) following CABG. Data on pharmacotherapy of individuals with registered MAEs were received in the hospital admission process of patients undergoing the event itself, or from archival medical records. In carrying out the analysis of archival records, data on pharmacotherapy immediately preceding the date of the event were taken into account. Among 55 patients with MAEs one patient did not have pharmacotherapy data of the follow-up. Thus, the total sample of patients analyzed for the frequency of intake of certain classes of cardiovascular drugs during the follow-up made up 250 people: 196 (78.4\%) no-MAEs patients and 54 (21.6\%) - with MAEs .

To assess patients' adherence to the recommendations during the follow-up data on the use of a group of drugs were compared with the information about its prescription at the end of in-hospital stay. Based on these comparisons, the studied cohort of patients was divided into 4 categories: 1) " $0-0$ " - a group of drugs not prescribed at the end of the in-hospital stay, neither used in the follow-up at the end of the in-hospital stay; 2) "0-1" - a group of drugs not prescribed at the end of the in-hospital stay, though taken by patients at the repeated encounter during the follow-up; 3 ) "1-1" the group prescribed at the end of the in-hospital stay; the patient continued to take it in the follow-up, (the indicator of "persistence" of administration [13]); 4) "1-0" - the group prescribed at the end of the in-hospital stay, yet not taken by patients in the follow-up.

Statistical analysis of the data was performed using the IBM SPSS Statistics v. 25.0 The comparison of the absolute and relative (\%) frequency of detection of qualitative indices in independent samples was performed using Pearson's $\chi 2$ criterion (in the " $2 \times 2$ " tables, taking into account the results of Fisher's exact test [FET]), dependent samples using McNemar's test: Determination of the association of qualitative characteristics was carried out using the V-criterion of Cramer (VC). The level of statistical significance was considered $\mathrm{p}<0,05$. 
Table I. Use of ACEI/ARBs at the end of in-hospital stay and in the follow-up, including the presence of MAEs .

\begin{tabular}{|c|c|c|c|c|c|}
\hline \multicolumn{2}{|c|}{ Frequency of use } & $\begin{array}{l}\text { In total } \\
\mathbf{n}=\mathbf{2 5 0}\end{array}$ & $\begin{array}{c}\text { Without MAEs } \\
n=196\end{array}$ & $\begin{array}{l}\text { With MAEs } \\
\quad n=54\end{array}$ & $\mathbf{p}_{1}$ \\
\hline \multicolumn{2}{|c|}{ At the end of in-hospital stay, $n(\%)$} & $217(86,8)$ & $174(88,8)$ & $43(79,6)$ & $0,109^{*}$ \\
\hline \multicolumn{2}{|c|}{ During the follow-up, $\mathrm{n}(\%)$} & $208(83,2)$ & $171(87,2)$ & $37(68,5)$ & 0,001 \\
\hline \multicolumn{2}{|c|}{$\mathrm{p}_{2}$} & 0,223 & 0,710 & 0,182 & - \\
\hline \multirow{4}{*}{ Use in the follow-up **, n (\%) } & $« 0-0 »^{2}$ & $16(6,4)$ & $9(4,6)$ & $7(13,0)$ & \multirow{4}{*}{0,011} \\
\hline & $\ll 0-1 »$ & $17(6,8)$ & $13(6,6)$ & $4(7,4)$ & \\
\hline & $\left\langle 1-1 »^{2}\right.$ & $191(76,4)$ & $158(80,6)$ & $33(61,1)$ & \\
\hline & $《 1-0 »^{2}$ & $26(10,4)$ & $16(8,2)$ & $10(18,5)$ & \\
\hline
\end{tabular}

Notes: $p_{1}$-significance of difference between groups without and with MAEs; $p_{2}$ - significance of difference in the frequency of use of a class of drugs in the follow-up; ${ }^{*}-\mathrm{pFET}^{* *}-\mathrm{V}_{\mathrm{c}}=0,211(\mathrm{p}=0,011) ;{ }^{2}$-significance of difference in z-test

Table II. Use of statins at the end of in-hospital stay and in the follow-up, taking into account the presence of MAEs

\begin{tabular}{|c|c|c|c|c|c|}
\hline \multicolumn{2}{|c|}{ Frequency of use } & $\begin{array}{l}\text { In total } \\
\mathbf{n}=\mathbf{2 5 0}\end{array}$ & $\begin{array}{c}\text { Without MAEs } \\
n=196\end{array}$ & $\begin{array}{l}\text { With MAEs } \\
\quad n=54\end{array}$ & $\mathbf{p}_{1}$ \\
\hline \multicolumn{2}{|c|}{ At the end of in-hospital stay, n (\%) } & $247(98,8)$ & $194(99,0)$ & $53(98,1)$ & 0,619 \\
\hline \multicolumn{2}{|c|}{ During the follow-up, $\mathrm{n}(\%)$} & $202(80,8)$ & $170(86,7)$ & $32(59,3)$ & $<0,001$ \\
\hline \multicolumn{2}{|c|}{$\mathrm{p}_{2}$} & $<0,001$ & $<0,001$ & $<0,001$ & - \\
\hline \multirow{3}{*}{ Use in the follow-up*, n (\%) } & «0-0» & $3(1,2)$ & $2(1,0)$ & $1(1,8)$ & \multirow{3}{*}{$<0,001$} \\
\hline & $\ll 1-1 »^{2}$ & $202(80,8)$ & $170(86,7)$ & $32(59,3)$ & \\
\hline & $《 1-0 »^{z}$ & $45(18,0)$ & $24(12,3)$ & $21(38,9)$ & \\
\hline
\end{tabular}

Notes: $p_{1}$-significance of difference between groups without and with MAEs; $p 2$-significance of difference in the frequency of use of a class of drugs in the follow-up; ${ }^{*}-V_{c}=0,289(p<0,001) ;{ }^{2}$-significance of difference in z-test

\section{RESULTS}

The analyzed cohort of patients was characterized by a high total level of ACEI/ ARBs prescription at the end of hospital follow-up in the comparable groups (Table I). However, in the MAEs group compared to the alternative group there was a lower proportion of patients taking RAS blockers in the follow-up dynamics.

In the analysis of various variants of ACEI/ ARBs use "trajectory" it was found that in the group with MAEs there was a greater proportion of patients from " $0-0$ " and "1-0" categories. The "persistence" rate of ACEI/ ARBs use ("1-1") was higher among the patients without any MAEs record during the three-year follow-up (Table I).

Whether prescription of ACEI/ ARBs is appropriate for patients with $\mathrm{CAD}$ after $\mathrm{CABG}$ is determined by the presence of concomitant arterial hypertension (AH), DM, left ventricular systolic dysfunction (LVSD) or CKD [1-3] in the vast majority of revascularized patients. Poor adherence to the use of RAS blockers could affect a number of important clinical aspects of CAD patient management after $\mathrm{CABG}$, lead to inadequate control of $\mathrm{AH}$ and lack of adequate neurohumoral blockade in the presence of HF, which probably increased the risk of MAEs. At the same time, discontinuation (or "non-prescription") of ACEI/ ARBs in the follow-up could be conditioned by hypotension and worsening functional state of kidneys $[1,2,4]$ in a number of patients.

Long-term use of statins and antiplatelet agents is a key aspect of drug therapy after revascularization procedures from the standpoint of influence on pathogenetic mechanisms of the onset and progression of atherosclerosis, as well as prevention of restenosis of grafts [20-23]. In the follow-up dynamics examined patients demonstrated significant differences in treatment with these drugs. In particular, at the end of the in-hospital stay statins were prescribed to the overwhelming majority of patients without any significant differences in the comparable groups (Table II). However, a decrease in the frequency of use of these drugs was registered in the follow-up. Moreover, in the MAEs group the proportion of patients who did not use statins in the follow-up was higher, both at the expense of a lower "persistence" (category "1-1") and a significantly higher percentage of those who discontinued prescribed statin therapy earlier (category " 1-0 "). Inadequate use of statins could increase the risk of adverse events after CABG in the long-term.

Previously data were obtained that statins reduce the risk of adverse cardiovascular events in the long-term after CABG, in particular in the context of inhibition of the venous grafts restenosis $[1,2,14-17]$. However, there remains a need to study the effects of statin therapy in the long-term follow-up following myocardial revascularization [18]. Inadequate dosing and suboptimal adherence to statin therapy in managing patients after myocardial revascularization are issues still to be solved [19].

The included sample of 250 patients was characterized by almost full coverage of APT recommended at the end of hospital follow-up, in particular in groups without and 
Table III. Use of APT in general at the end of in-hospital stay and in the follow-up, taking into account the presence of MAEs

\begin{tabular}{|c|c|c|c|c|c|}
\hline \multicolumn{2}{|c|}{ Frequency of use } & $\begin{array}{l}\text { In total } \\
n=250\end{array}$ & $\begin{array}{l}\text { Without MAEs } \\
\quad n=196\end{array}$ & $\begin{array}{c}\text { With MAEs } \\
n=54\end{array}$ & $\mathbf{p}_{1}$ \\
\hline \multicolumn{2}{|c|}{ At the end of in-hospital stay, n (\%) } & $248(99,2)$ & $195(99,5)$ & $53(98,1)$ & 0,327 \\
\hline \multicolumn{2}{|c|}{ During the follow-up, n (\%) } & $227(90,8)$ & $180(91,8)$ & $47(87,0)$ & 0,280 \\
\hline \multicolumn{2}{|l|}{$\mathrm{p}_{2}$} & $<0,001$ & $<0,001$ & 0,041 & - \\
\hline \multirow{4}{*}{ Use in the follow-up, $\mathrm{n}(\%)$} & «0-0» & $1(0,4)$ & 0 & $1(1,9)$ & \multirow{4}{*}{0,221} \\
\hline & «0-1» & $1(0,4)$ & $1(0,5)$ & 0 & \\
\hline & «1-1» & $226(90,4)$ & $179(91,3)$ & $47(87,0)$ & \\
\hline & «1-0» & $22(8,8)$ & $16(8,2)$ & $6(11,1)$ & \\
\hline
\end{tabular}

Notes: $p_{1}$-significance of difference between groups without and with MAEs; $p_{2}$-significance of difference in the frequency of use of a class of drugs in the follow-up;

Table IV. Use of the combination «ACEI or ARBs / statin / anti-platelet» at the end of in-hospital stay and in the follow-up, taking into account the presence of MAEs

\begin{tabular}{|c|c|c|c|c|c|}
\hline Frequency of use & & $\begin{array}{l}\text { In total } \\
n=250\end{array}$ & $\begin{array}{l}\text { Without MAES } \\
n=196\end{array}$ & $\begin{array}{l}\text { With MAES } \\
n=54\end{array}$ & $\mathbf{p}_{1}$ \\
\hline At the end of in-hospital stay, n (\%) & & $213(85,2)$ & $171(87,2)$ & $42(77,8)$ & 0,083 \\
\hline During the follow-up, n (\%) & & $157(62,8)$ & $138(70,4)$ & $19(35,2)$ & $<0,001$ \\
\hline $\mathrm{p}_{2}$ & & $<0,001$ & $<0,001$ & $<0,001$ & - \\
\hline \multirow{4}{*}{ Use of the combination in the follow-up*, n (\%) } & $\ll 0-0 »^{z}$ & $23(9,2)$ & $14(7,1)$ & $9(16,7)$ & \multirow{4}{*}{$<0,001$} \\
\hline & $\ll 0-1 »$ & $14(5,6)$ & $11(5,6)$ & $3(5,6)$ & \\
\hline & $\ll 1-1 »^{2}$ & $143(57,2)$ & $127(64,8)$ & $16(29,6)$ & \\
\hline & $« 1-0 »^{2}$ & $70(28,0)$ & $44(22,5)$ & $26(48,1)$ & \\
\hline
\end{tabular}

Notes: $p_{1}$-significance of difference between groups without and with MAEs; $p_{2}$ - of difference in the frequency of use of a class of drugs in the follow-up; $*-V_{c}=0,305(p<0,001) ;{ }^{2}$-significance of difference in z-test

with MAEs (Table III). It should be noted that in the majority of cases during 6 months after CABG dual APT was used followed by monotherapy with ASA or clopidogrel.

Adherence to the use of APT was the highest among the basic pharmacotherapy agents for $\mathrm{CAD}$. In both compared groups the overwhelming majority (about $90 \%$ ) of patients continued to use APT (category 1-1) in the long-term follow-up.

The most sensitive indicator of compliance with postoperative pharmacotherapy guidelines is the frequency of use of basic three-component combination therapy (ACEI inhibitor or ARBs / statin / antiplatelet [12]). In the general sample of patients this indicator was $85.2 \%$ at the end of in-hospital stay without significant differences in the comparable groups (Table IV). In the follow-up dynamics attention was drawn to the lower "persistence» of prescribed therapy in patients from MAEs group where only $38.1 \%$ (16 of 42 patients) continued to receive this combination immediately before the event (Table IV). In contrast, in the group of patients without late events, almost two thirds of patients continued to receive the prescribed basic treatment three years after CAD $(74.2 \%$ (127 out of 171 patients) versus $38.1 \%$ in the MAEs group; $\mathrm{p}<0.001)$.

Inadequate use of the basic three-component combination therapy could be one of the factors associated with increased risk of MAEs in the long-term after CAD. It should be taken into account that a decrease in the frequen- cy of basic three-component therapy in the follow-up was mainly due to the premature termination of therapy with RAS blockers and statins, rather than APT.

\section{DISCUSSION}

Poor adherence to medical treatment is a commonly recognized problem in the management of patients with cardiovascular diseases. According to American researchers [20], annually 125,000 deaths which could have been otherwise prevented are associated with insufficient adherence to prescribed drugs, since only about half of patients consistently adhere to the prescribed pharmacotherapy. Thus, long-term intake of basic pharmacotherapy and optimization of drug adherence are one of the key aspects for the improved clinical outcomes in treating patients with CAD.

Correspondence of prescriptions to existing guidelines and adherence to the recommended treatment are suboptimal and worse in patients who underwent $\mathrm{CAD}$ compared to those with CAS. In particular, the study by A. Pihno-Gomes et al. [3] shows significant differences in the frequency of use of a combination of four drugs (ACEII or ARBS / BB / statin / antiplatelet) and unsatisfactory levels of adherence to treatment following myocardial revascularization. Despite significant heterogeneity the best indicator of adherence to this combination at one year follow-up was only $56.7 \%$ 
(in the FREEDOM study [24]). Moreover, there was some decrease in adherence over time. However, in real practice, adherence rates are much lower than in clinical trials [21].

Insufficient level of the use of basic agents in secondary prevention of cardiovascular events after CABG in actual clinical practice is brought about by various reasons. Namely, underestimation of the importance of preventive pharmacotherapy, as well as misconceptions about the lack of benefit of such treatment in patients with CAD, whose myocardial flow was mechanically recovered $[22,25,26]$. In this regard, studies on the effectiveness of revascularization often neglect data on drug therapy [27]. It should be emphasized that in controlled clinical trials the highest level of adherence to prescribed treatment is usually achieved [3]. In one of them the levels of "persistence» in patients receiving $\mathrm{APT}, \mathrm{BB}, \mathrm{ACEI} / \mathrm{ARBs}$ and statins 16 months on average after CAD (according to patients self reports ) was $98 \%, 86 \%, 88 \%$, and $92 \%$ respectively [13].

Consideration should be given to the potential limitations of clinical interpretation of the obtained results, namely: retrospective nature of the study; frequency of the drug use in the follow-up as a surrogate indicator of adherence; in some cases the lack of complete information on the pharmacotherapy regimens as well as possible objective reasons for discontinuing certain drugs.

\section{CONCLUSIONS}

The emergence of MAEs within three years after isolated CABG in patients with stable CAD, including those with concomitant LV systolic dysfunction, was associated with inadequate use and more frequent discontinuation of basic pharmacotherapy, in particular, RAS blockers (ACEI inhibitors /ARBs) and statins, and three-component therapy (ACEI or ARBs / statin / anti-platelet). To reduce the risk of cardiovascular complications at the late stages after surgical revascularization of the myocardium it is of great importance to comply with the existing guidelines for the basic pharmacological therapy of stable CAD and ensure adherence to the prescribed treatment.

\section{REFERENCES}

1. Kulik A., Ruel M., Jneid H. et al. Secondary prevention after coronary artery bypass graft surgery. Circulation. 2015;131(10):927-964. doi: 10.1161/CIR.0000000000000182.

2. Sousa-Uva M., Head S., Milojevic M. et al. 2017 EACTS Guidelines on perioperative medication in adult cardiac surgery. Eur I Cardiothorac Surg. 2017;53(1):5-33. doi: 10.1093/ejcts/ezx314.

3. Pinho-Gomes A., Azevedo L., Ahn J. et al. Compliance with guidelinedirected medical therapy in contemporary coronary revascularization trials. JACC. 2018;71(6):591-602. doi: 10.1016/j.jacc.2017.11.068.

4. Ponikowski P., Voors A., Anker S. et al. 2016 ESC Guidelines for the diagnosis and treatment of acute and chronic heart failure. Eur Heart J. 2016;37(27):2129-2200. doi: 10.1093/eurheartj/ehw128.

5. Pakpour A., Gellert P., Asefzadeh S. et al. Intention and planning predicting medication adherence following coronary artery bypass graft surgery. J Psychosom Res. 2014;77(4):287-295. doi: 10.1016/j. jpsychores.2014.07.001.
6. Ali M., Yasir J., Sherwani R. et al. Frequency and predictors of nonadherence to lifestyle modifications and medications after coronary artery bypass grafting: A cross-sectional study. Indian Heart J . 2017;69(4):469-473. doi: 10.1016/j.ihj.2017.05.017.

7. Sengstock D., Vaitkevicius P., Salama A. et al. Under-prescribing and nonadherence to medications after coronary bypass surgery in older adults. Drugs \& Aging. 2012;29(2):93-103. doi: 10.2165/11598500-000000000-00000.

8. Drenger B., Fontes M., Miao Y. et al. Patterns of use of perioperative angiotensin-converting enzyme inhibitors in coronary artery bypass graft surgery with cardiopulmonary bypass. Circulation. 2012;126(3):261-269. doi: 10.1161/CIRCULATIONAHA.111.059527.

9. Griffo R., Ambrosetti M., Tramarin R. et al. Effective secondary prevention through cardiac rehabilitation after coronary revascularization and predictors of poor adherence to lifestyle modification and medication. Results of the ICAROS Survey. Int J Cardiol. 2013;167(4):1390-1395. doi: 10.1016/j.jijcard.2012.04.069.

10. Szychta W., Majstrak F., Opolski G. et al. Trends in pharmacological therapy of patients referred for coronary artery bypass grafting between 2004 and 2008: a single-centre study. Kardiol Pol. 2015;73(12):13171326. doi: 10.5603/KP.a2015.0094.

11. KDIGO 2012 Clinical Practice Guideline for the evaluation and management of chronic kidney disease. Kidney Int Suppl. 2013;3(1):1-150.

12. $2013 \mathrm{ESC}$ guidelines on the management of stable coronary artery disease. Eur Heart J. 2013;34(38):2949-3003. doi: 10.1093/eurheartj/eht296.

13. Khanderia U., Townsend K., Erickson S. et al. Medication adherence following coronary artery bypass graft surgery: assessment of beliefs and attitudes. Ann Pharmacother . 2008;42(2):192-199. doi: 10.1345/ aph.1K497.

14. Philip F., Blackstone E., Kapadia S. Impact of statins and beta-blocker therapy on mortality after coronary artery bypass graft surgery. Cardiovasc Diagn Ther. 2015;5(1):8-16. doi: 10.3978/j.issn.22233652.2015.02.01.

15. Kang S., Liu Y., Liu X. Effects of aggressive statin therapy on patients with coronary saphenous vein bypass grafts: a systematic review and metaanalysis of randomized, controlled trials. Clin Ther. 2013;35(8):11251136. doi: 10.1016/j.clinthera.2013.06.006.

16. Bin C., Junsheng M., Jianqun Z. et al. Meta-analysis of medium and long-term efficacy of loading statins after coronary artery bypass grafting. Ann Thorac Surg . 2016;101(3):990-995. doi: 10.1016/j. athoracsur.2015.08.075.

17. Kulik A. Secondary prevention after coronary artery bypass graft surgery. Curr Opin Cardiol. 2016;31(6):635-643. doi: 10.1097/ HC0.0000000000000331.

18. Kulik A., Abreu A., Boronat V. et al. Intensive versus moderate atorvastatin therapy and one-year graft patency after CABG: Rationale and design of the ACTIVE (Aggressive Cholesterol Therapy to Inhibit Vein Graft Events) randomized controlled trial (NCT01528709). Contemp Clin Trials. 2017;59:98-104. doi: 10.1016/j.cct.2017.06.006.

19. Curl K., LeBude B., Ruggiero N. et al. Frequency of use of statins and aspirin in patients with previous coronary artery bypass grafting. Am J Cardiol. 2016;118(1):40-43. doi: 10.1016/j.amjcard.2016.04.006.

20. Ferdinand K., Senatore F., Clayton-Jeter H. et al. Improving medication adherence in cardiometabolic disease. JACC. 2017;69(4):437-451. doi: 10.1016/j.jacc.2016.11.034.

21. Achelrod D., Gray A., Preiss D. et al. Cholesterol- and blood-pressurelowering drug use for secondary cardiovascular prevention in 2004-2013 Europe. Eur J Prev Cardiol. 2016;24(4):426-436. doi: $10.1177 / 2047487316676906$. 
22. Marcum Z., Sevick M., Handler S. Medication nonadherence. JAMA. 2013;309(20):2105-2116. doi: 10.1001/jama.2013.4638.

23. Oosterga M., Voors A., Pinto Y. et al. Effects of quinapril on clinical outcome after coronary artery bypass grafting (the QUO VADIS study). Am J Cardiol. 2001;87(5):542-546. doi: 10.1016/s0002-9149(00) 01428-4.

24. Farkouh M., Domanski M., Sleeper L. et al. Strategies for multivessel revascularization in patients with diabetes. N Engl J Med. 2012;367(25):2375-2384. doi: 10.1056/NEJMoa1211585.

25. Hlatky M., Solomon M., Shilane D. et al. Use of medications for secondary prevention after coronary bypass surgery compared with percutaneous coronary intervention. JACC. 2013;61(3):295-301. doi: 10.1016/j. jacc.2012.10.018.

26. Kulik A., ShrankW., Levin R. et al. Adherence to Statin Therapy in elderly patients after hospitalization for coronary revascularization. Am J Cardiol.2011;107(10):1409-1414. doi: 10.1016/j.amjcard.2011.01.013.

27. Mäkikallio T., Holm N., Lindsay M. et al. Percutaneous coronary angioplasty versus coronary artery bypass grafting in treatment of unprotected left main stenosis (NOBLE): a prospective, randomised, open-label, non-inferiority trial. Lancet. 2016;388(10061):2743-2752. doi: 10.1016/50140-6736(16)32052-9.
The study was conducted as a fragment of the complex scientific project of the Department of Heart and Vascular Pathology Diagnostics (Heart Institute of the Ministry of Health of Ukraine) «Scientific validation of efficacy of myocardial revascularization for patients with coronary artery disease» (state registration number 0116U008820; term: 2016-2018).

\section{ORCID and contributorship:}

Olga A. Yepanchintseva - 0000-0001-7054-1564 ${ }^{A, B, C, D}$

Kyrylo O. Mikhaliev - 0000-0003-3759-6699 ${ }^{B, C, D}$

Inga V. Shklianka - 0000-0002-4974-1059 B,C

Oleg J. Zharinov - 0000-0002-4089-9757 ${ }^{A, E, F}$

Boris M. Todurov - 0000-0002-9618-032X ${ }^{E, F}$

\section{Conflict of interest:}

The Authors declare no conflict of interest.

\section{CORRESPONDING AUTHOR}

Olga A. Yepanchintseva

Department of Heart and Vascular Pathology Diagnostics

Heart Institute of the Ministry of Health of Ukraine

Bratyslavska str., 5 A, 02660 Kyiv, Ukraine

tel: +380679929152

e-mail: 0.epanoly@gmail.com

Received: 23.01 .2020

Accepted: 31.03 .2020

A - Work concept and design, B - Data collection and analysis, C - Responsibility for statistical analysis,

D-Writing the article, $\mathbf{E}$-Critical review, $\mathbf{F}$ - Final approval of the article 